\title{
CULTURA MODERNA E CAMPO CONSERVADOR NO BRASIL
}

TALES A.M. AB'SÁBER discute os traços conservadores da modernidade brasileira

\section{HIPÓTESE DE FUNDO}

O Brasil é país moderno por excelência. Mas este espaço social tão particular adentrou de fato a modernidade com dois grandes atravessamentos não modernos, que compõem tanto a sua estrutura econômica original quanto a sua lógica político, simbólica e cultural, mais profunda. Trata-se da escravidão, e sua economia eminentemente rural, mas global, e da origem política institucional com um específico ancien règime, atrasado, ibérico português. Originalmente e durante praticamente todo o século XIX, o século da explosão industrial europeia e americana, e sua ideologia do progresso imanente, o Brasil foi de fato um Império Constitucional de economia rural escravista. Em relação à medida externa, dada necessariamente pelo lugar do país nos fluxos das trocas globais, estas duas forças que representaram os móveis maiores da fundação do espaço nacional tropical póscolonial, são forças simplesmente reacionárias, explicitamente não modernas, cuja organicidade é a própria conservação de seus princípios, marcados por um outro plano de nacionalidade. E em relação ao desenvolvimento capitalista mais geral, pelo atraso. Trata-se de forças culturais de conservação de estruturas tradicionais, e não de transformação, de destruição e de criação, como era a dinâmica mais ampla da própria modernidade.

\section{EXCURSO}

O movimento de grande duração que inscreveu o Brasil e os demais países americanos na história mais ampla da modernidade, de modo a estabelecer no descobrimento do espaço colonial e do novo espaço simbólico americano um dos verdadeiros fundamentos da experiência e do conceito da ordem moderna em expansão, costuma nos iludir a respeito do estatuto por vezes travado, por vezes fortemente regressivo, em grande medida conservador, de uma vida social contraditória de um modoespecífico, e que em grande medida regula a pulsação da experiência da cultura entre nós.

Somos tradicionalmente condenados à modernidade, de fato e por ideologia. A natureza atravessada de iberismo, catolicismo, patriarcalismo, clientelismo e elitismo exclusivista, com espaço público universal simplesmente inexistente, que fundou de fato a nação brasileira, em um processo sucessivo de marcas afirmativas e retardamentos efetivos em sua outra experiência de modernidade política e 
econômica - seu mercado internacionalizado com mão-de-obra escrava e uma mínima casta de homens brasileiros livres - costuma ser comumente esquecida ao se dar nome à cultura por estas bandas, frente aos princípios mais dignos e imaginariamente excitantes de uma modernidade compulsória, que deveria se realizar mesmo que a golpes de machado imaginários.

O fato, de duração de quatrocentos anos, de termos entrado e nos posicionado no processo da modernidade ocidental pela porta de trás da escravidão de massas dos capitalismo mercantil do séculos XVII e XVIII, matriz radical e pregnante geradora de um milhão de formas do atraso em nosso espaço social real - como, ao seu tempo, Joaquim Nabuco já apontou com precisão - costuma ser evitado com sistema quando nos aproximamos da cultura, e o seu nome, entre nós. Tal cuidado é contínuo, sintoma simbólico e social primeiro, para que tentemos, com mais ou menos eficácia, nos elevar da tradicional descontinuidade de densidade de problemas significativamente modernos, de modo a que se possam produzir simulacros desejados da ordem da integração social das massas e do ganho de democracia simbólica e material, o que, até muito recentemente no Brasil não passava de ilusão histórica, magicamente autorrealizada. No entanto, no plano da cultura e da arte, lugar imaginário por excelência, durante muito, e de muitos modos, o Brasil podia não ser o Brasil, o que era um modo muito próprio de ser o Brasil.

Durante muito tempo o verdadeiro problema moderno brasileiro foi o terror ocidental colonial deixado de herança a uma nação, moderna, mas que mal se diferenciava das marcas de sua formação também radicalmente exteriorizada. Todavia, simultaneamente e no plano da cultura, era exatamente este ponto o que de fato não poderia ser dito. O elogio de uma elite cultural à escravidão moderna, como ela aparece na obra e no posicionamento político explícito de um José de Alencar, por exemplo, desconsiderava amplamente o processo propriamente moderno central e sua produtividade orgânica, da solução de compromisso instável contratada entre as classes sociais, de onde emergiu, já no século XIX, a vanguarda estética antiburguesa europeia.

Noutra via, o precoce "eu também já fui brasileiro, já fui moreno como vocês", do modernista de segunda geração Carlos Drummond de Andrade, certamente indicava saudável liberdade para a desidentificação de um excesso ideológico que há muito sobrecarregava o espaço da ação e do pensamento com um nacionalismo compensatório e de longa duração, advindo do romantismo pastoral, decoroso e alegorizante da criação de um espaço nacional praticamente do nada, durante o longo e lento século Imperial brasileiro e, no entanto, tal visada livre e superior do homem urbano do século XX sinalizava também a facilidade da reversão imediata a um cosmopolitismo igualmente mágico e positivo, o transoceanismo congênito 
e constante próprio de nossa posição periférica e retardatária, de um espaço social reflexo, na noção precisa de Paulo Duarte.

Oscilando entre as comoções de singularidade e identidade alucinada de uma vida autocne e por subtração da cultura nacional, de elite de violenta nobreza escravocrata, e uma internacionalização redentora e esvaziadora da consciência própria do tempo e do lugar, de uma própria dialética particular da modernidade, seguia grande parte do impulso cultural da modernidade singular do país lusotropical, de raíz escravista. Daí a concentração máxima dos dois polos da equação na ideia precisa de estrangeiros em nossa própria terra de Sérgio Buarque de Holanda, e seu complemento dialético avançado, e ainda mais perfeito, da ordem de uma antropofagia negativa, do "oscilamos constantemente entre não ser e ser o outro", da dialética rarefeita de Paulo Emílio Salles Gomes, sínteses conceituais críticas do século XX do que arduamente se conquistou na vida da melhor experiência estética por estas paragens, a partir da radicalidade machadiana e do agiornamento dialético modernista naquilo que ele conheceu de mais radical.

Por outro lado, e em outra chave dos mesmos motivos, Glauber Rocha podia iniciar com toda precisão a sua reflexão profunda sobre o golpe de $1964 \mathrm{com}$ a imagem do encontro alegórico do nobre português de carnaval, com o índio autócne desenraizado e com o negro escravo, na praia e no sol do Brasil, e, ainda em 1967, na obra-prima de ampla e longa duração que foi Terra em Transe o sentido do presente o do futuro conservadores brasileiros, o golpe de 1964 e a configuração autoritária de nosso capitalismo sempre incompleto, se sobrepunha amplamente à imagem histórica onipresente da fundação ibérica escravista brasileira. Uma leitura do andamento da história, bem realizada pela própria forma do filme, é que por estas bandas não adentramos a ideia de linearidade do progresso abstrato, própria do mundo central, mas habitamos uma forma de circularidade histórica, em que, nos momentos decisivos, é o passado que se impõe ao presente, e não o futuro.

Tal imagem dialética, alegoria modernista clássica, raíz do Brasil, que alcançava agora o cinema que finalmente alcançava a própria revolução modernista brasileira, era simplesmente, naquele conjuntura de regressão histórica produtiva, uma imagem da verdade. A crise de radical modernidade, signo de um momento decisivo na história do presente e da guerra fria dos anos de 1950 e 60, que decidia o destino da humanidade no século XX avançado, desaguava por estas bandas na simples reafirmação da clivagem social mais radical, cujas origens mais singelas e puras, segundo o filme, recuavam à fundação do escravismo brasileiro e do sistema escravista do Antlântico Sul, que uniu Portugal, África e Brasil, nos séculos XVII e XVIII, aproximando, como Luiz Felipe de Alencastro demonstrou, mais a Bahia e Pernambuco de Moçambique e de Angola do que de 
São Paulo. E o artista, atento à densidade do fato histórico de superfície, reconhece a profundidade estrutural de um processo de violência especial da modernidade, chamado Brasil, que simplesmente não passava.

É certo que existe uma forte leitura da ordem da cultura entre nós que busca sempre sintonizar o momento de ponta de uma possível vanguarda artística, que tenha se autonomizado e se tornado autoconsciente, mais ou menos como acabei de fazer com Glauber Rocha, o momento em que, de modo particular, poderíamos igualar os problemas de forma e vida do espírito de uma ordem central que, no imenso das vezes, representa verdadeira medida e referência para a cultura e a sociedade materialmente atrasada, comumente ultrapassada. De par com o esforço menos excitante e não fetichista de estabelecer o solo ríspido e por vezes rebaixado de uma experiência histórica traduzida em cultura e arte muitas vezes acanhada, pouco efetiva formalmente, reflexa e incompleta em relação às próprias más pretensões de nação inserida no processo ocidental, existe um verdadeiro movimento positivo, mesmo que abstrato, de afirmação de um último gesto ou grito de uma modernidade inevitável, redimida na experiência isolada de uma solução de ponta, capaz de imantar e contaminar a sabida e recalcitrante descontinuidade produtiva e formal do todo. O que no processo central se deu de fato como o embate entre modernização real controlada e modernismo crítico de vanguarda, entre nós se deu em um movimento de três polos conflitantes, entre modernização, modernismo de superfície e forte reação conservadora, também sempre conservada.

Nesta vertente das coisas de cultura buscamos também algo da redenção social a golpes de gênios, que isoladamente, verdadeiramente, projetam uma civilização que simplesmente não se confirma ao redor. Embora paradoxalmente tenha chegado a providenciar os elementos de sua formação, o processo sempre enigmático da formação do gênio e do artista completo no panorama esmaecido de uma realidade empobrecida, marcada pela continuidade do pior. Assim costumamos sempre resgatar nossos pontos altos, sejam eles literários, artísticos, cinematográficos, musicais, como modo de invocar, a cada solução histórica alcançada, a imagem de um todo potencialmente redimido no fato estético simbólico do artista superior ter vencido o Brasil, no gesto de norma elevada e costumeiramente de alta modernidade que aparece por aqui de tempos em tempos, e que deveria servir ao todo da cultura, sistematicamente em déficit exemplar.

E no entanto, na maioria das vezes, tal esforço histórico que pertence ao todo mal serve ao própria artista criador, na sua figuração fragmentária de uma superação que gira em falso de um sistema cultural constantemente insólito, em sua Aufhebung de câmera, particular. 


\begin{tabular}{ll|l}
\hline celeuma & número $1 \mid$ volume $1 \mid$ maio 2013 & dossiê
\end{tabular}

Com exceção dos campos de cultura popular que se desenvolveram à parte e apesar das distorções autoritárias e antipopulares mais verdadeiras das elites nacionais, - a famosa aristocracia do nada de Paulo Emílio Salles Gomes, em uma nomeação própria do tempo em que o intelectual público ainda confrontava o campo conservador brasileiro - como o da música popular, com destaque para a especial experiência negra e favelada do samba clássico brasileiro, e seu rebatimento no corpo erótico da dança, que fascinou a vanguarda radical de um Hélio Oiticica, e o do futebol, em que Pelé e Garrincha representaram o auge de um universo técnico formado que estabeleceu uma historia contínua, de alto repertório e imanente dos pobres que seguiu relativamente constante do final da década de 1930 até o presente, em muitas das demais artes e belas artes, as herdadas do processo europeu, o Brasil pode produzir, ao longo do século XIX e XX, gênios particulares, em momentos de pico de grande amplitude de vista histórica e de radical solução formal, de interesse universal. E, no entanto, na maioria das vezes tais gestos fortes eram ligados a campos fragilizados, para não falarmos do campo geral da cultura não integra, que não repercutia a obra de seus autores maiores como experiência geral de transformação, ou mesmo no nível desejado de técnica do tempo.

Curiosamente, neste tipo de dialética brasileira entre a vida longa e a arte breve, a cultura desarticulada e repetitiva e o artista com seu momento de universal modernidade, o impacto maior do instante tropicalista de fins dos anos de 1960, movimento estético histórico que tocou o nervo mais amplo de seu tempo, se deu pela recuperação estratégica, de longa duração, do modernismo dialético então bastante isolado de Oswald de Andrade, e da repercussão da obra forte de alguns jovens gênios de classe média, diante do todo radicalmente clivado e do controle e do fechamento do espaço público estabelecido pela ditadura militar conservadora, para uma sociedade que descarrilava a tênue tentativa histórica, de pelo menos trinta anos, de finalmente se configurar através de uma plena revolução moderna e modernizadora, derrotada. Foi a tomada do todo pelo poder arcaíssimo que insistia em definir os rumos conservadores da nação, articulado a um capitalismo de integração social via mercado, então desconhecido, que destacou a força de um movimento de grandes qualidades de vanguarda e de leitura mais ampla, mesmo que alegórica, das contradições do país, no tempo e no espaço contemporâneos ao seu próprio gesto. De modo que a força mesma de totalização do movimento, que visava conceber-se como comunicação de massa no momento da emergência da unificação da experiência de massas, padronizada pela televisão, foi impulsionada pelo todo, voltado francamente à força e à manutenção de um país não integrado. Terra em transe.

O fragmento de contradição tropicalista se completava, em uma estranha 
dialética, na força decisiva do inimigo histórico de qualquer modernização consequentemente democrática no país, e, exatamente como Oswald de Andrade realizou nas vésperas da revolução 1930, se tirava a máxima força crítica do lugar escandaloso, e de visada dialética, da própria mais ampla derrota histórica...

Noutras palavras, o campo conservador impulsionou a expansão, que não se tornou hegemônica, mas passou a marcar o pulso da cultura no momento da universalização da comunicação de massas no país, do próprio campo crítico mais radical nacional, naquele momento histórico raramente contracultural em relação ao Brasil, sempre movido a uma modernidade edificante. E por isso, em relação dialética com a própria derrota histórica, tais artistas acabaram por contaminar o todo fraturado, a vida social mais ampla, que concebiam na própria técnica de sua forma típica, o discurso alegórico técnico arcaico e erótico tropicalista.

Nossa tentativa constante de produzir uma indução de continuidade em uma cultura até ontem descontínua, e de experiência social clivada muitas vezes, não nos permitiu uma leitura acurada da natureza do campo conservador brasileiro, a verdadeira força ativa de integração e simultânea não integração, progresso e simultâneo atraso irredimido, espírito nacional e simultaneamente dependência internacional das formas do capital de cada tempo, de cada ciclo, econômico, de reedição das mazelas nacionais. Não estudamos suficientemente nossas formas de conservar o Brasil no seu passado constantemente modernizado, que nunca passa, os sistemas de concepção de mundo e história que mais ou menos sistematicamente mantiveram o país sobre o registro da clivagem social mais radical. Qual cultura moderna brasileira foi a que conviveu com tal natureza de modernização constante sem modernidade?

\section{SITUAÇÃO CONTEMPORÂNEA}

No espaço histórico de longa duração do Brasil o mercado antecedeu em larga escala o Estado nacional e o Estado nacional antecedeu fortemente à nação moderna socialmente integrada. Assim não é surpresa a construção política hegemônica do presente de uma modernização de mercado muito acelerada, com democracia efetivamente incompleta.

Vivemos de fato um deslocamento do lugar de atraso histórico, um poderoso agiornamento ideológico, em uma sincronização simbólica com o centro da experiência capitalista, do ponto de vista da experiência de um mercado mundial aberto, próprio do consumidor mundial, da cultura globalizada de mercado, contudo, no nosso caso, sem completar os elementos fundamentais próprios à integração de uma nação moderna: educação pública e de massas minimante qualificada, direito à cidade e a moradia dignas, saúde universal, direitos humanos efetivos não conspurcados, imputabilidade para a elite dirigente e econômica e 
autonomia crítica do indivíduo que possa alcançar e definir mesmo o estatuto do espaço republicano.

Vivemos hoje a situação de um Estado articulado entre promover desenvolvimento econômico árduo, pela presença constante do atraso científico e tecnológico, bem como pela ausência de uma cultura local mais profunda de inovação de mercado, de investimento e de formação de capitais criativos locais - após a radical financeirização neoliberal dos anos de 1990 - e iludir constantemente as demandas sociais ainda básicas em um processo de adiamento, de suspensão infinita dos direitos, que devem ser resolvidos em algum pacto simbólico ideológico entre a vida popular e o poder. Neste ponto os mecanismos de controle social e de ilusão espetacular da indústria cultural completam o processo de suspensão ao infinito, ideologia espetacular, próprio do novo Estado brasileiro: o modo brasileiro de funcionamento dos aparelhos ideológicos de Estado. Evidentemente sem prejuízo do Brasil ser o país em que mais morrem pessoas assassinadas no mundo, com a expressiva participação da polícia neste verdadeiro extermínio normal local, deslocado e concentrado na vida dos muito pobres e jovens.

Com o governo de esquerda se completou uma solução simbólica orgânica para esta simulação de política, realizada no desejo de poder, arcaico, inclusive nas classes médias e pobres envolvidos, da transferência carismática ao corpo do líder amado. Se completa o círculo infernal, pósmoderno ao modo local, da simulação da política.

O problema talvez seja verificarmos se também não temos, diante da cultura totalitária do desejo de mercado, da fragilidade e da simulação da política, uma verdadeira simulação da cultura, que se tornou em grande medida muito superficial e cínica. Assim no campo da cultura, e seu contemporâneo potencial conservador brasileiro, podemos circunscrever seis tipos de mundos diferentes, que criam o circulo infernal de uma sociedade ainda atravessada por radicais arcaísmos e que funciona, que funciona como sociedade contemporânea:

a) Uma cultura de massas baixa, que mal serve para as negociações pós-modernas de tipo americano. Inclusive porque há cisão ainda radical entre elite cultural orientada pelo grande plano cultural do ocidente, sempre atrasado e em falso por estas bandas, e a vida popular, orientada por sua própria história de violências e soluções simbólicas particulares.

b) Uma cultura de massas que negocia seu trânsito em todas as esferas e classes da vida nacional: algo do samba clássico de da música popular, cujos artistas são finalmente transformados em gênios da raça e, principalmente, o futebol. 
Esta espécie de cultura média brasileira é o lugar do novo pacto de conciliação e celebração das condições nacionais do presente. Neste ponto se inscrevem os portais e redes sociais da internet, e o mundo da indústria cultural pesada da teledramaturgia. O correlato prático desta cultura é generalização da cultura como consumo.

c) Uma cultura de elite, cult, ainda reflexa, sempre enquadrada pelos grandes movimentos centrais, no cinema, de padrão irrealizável, mas também em vários aspectos das artes plásticas, da literatura e do consumo cultural contemporâneo.

d) A tentativa de produção, com um olho no processo central, e outro na história local, em uma espécie de modernismo retardatário e colocado em cheque pelo nível atual de produtividade do pacto arte fetichismo dinheiro, da grande business art central, de uma visada própria para o estado fragmentário, banalizado, utilitarista e sem dimensão da nossa própria cultura. Uma tentativa de encetar uma visada própria, não mais escandalosamente antropofágica, ou tropicalista marginal, mas sim elevada, um pouco em falso, e melancólica, dado o reconhecimento da distância constante frente a produtividade capitalista central, apenas impossível por estas bandas, cultura que parece chegar agora a um nível de mercado que os Estados Unidos conheceu nos anos de 1950.

e) A cultura de circulação de imagens de ego, de propaganda, em correspondência direta com a mercadoria, do balcão de ofertas mistificadores do si mesmo, no espaço público rebaixado da internet, ou mesmo em espaços do jornalismo rebaixado até este ponto. Ali se ofertam sujeitos para tudo, e o espaço da circulação da mercadoria também se realiza simultaneamente, de modo semelhante ao da circulação das pessoas.

f) Em meio a isto tudo uma cultura crítica, na universidade e em novos dispositivos culturais curiosos e elegantes, novas revistas e institutos, para dar voz aos cultos entre si, que tentam dar alguma dimensão ao pensamento entre nós, considerando o enquadramento da crítica pela indústria cultural de jornais e revistas totalmente voltados para a cultura da reprodução e circulação estrita da mercadoria e da sua autoimagem de propaganda. Esta cultura é de fato mínima, acabando por funcionar como ilustração de elite.

Por fim, o intelectual público moderno, entre nós convocado historicamente pelo impulso profundo de construir a nação ao mesmo tempo que critica-la, parece ter se tornado uma figura plenamente dispensável em tal ordem industrial, mas rebaixada de modo próprio, das coisas locais. Do mesmo modo que a política se aproxima perigosamente da determinação estrita dos grandes mercados globais, a cultura se realiza na identidade cada vez mais total com o espaço simplificado 
da plena imagem e da circulação em grande escala da mercadoria. Mas, evidentemente, teremos um espaço de simulacro para uma cultura elevada e até mesmo para uma cultura crítica entre nós.

Evidentemente sempre teremos esforços de artistas, grupos e obras de arte isoladas, com mínimos sistemas culturais correlatos, mas fracos, como foram os nossos Machado, Oswald, Drummond, Niemeyer, João Gilberto, Glauber, Hélio, para sinalizar o momento atual do vínculo Brasil mundo, e para trazer o mundo até a nossa experiência histórica das coisas, mesmo que a contrapelo de toda verdadeira violência incorporada e desrealizada nas consciências, mais própria da nação dependente e humanamente atrasada.

TALES A.M. AB'SÁBER é psicanalista e professor de filosofia da psicanálise na Universidade Federal de São Paulo (Unifesp), autor de, entre outros, O sonhar restaurado (Editora 34) e Lulismo, carisma pop e cultura anticrítica (Hedra). 